\title{
Dairy farmers' perceptions toward the implementation of on-farm Johne's disease prevention and control strategies
}

\author{
C. Ritter, ${ }^{* 1}$ J. Jansen, $†$ K. Roth, ${ }^{*}$ J. P. Kastelic, ${ }^{*}$ C. L. Adams, $\ddagger$ and H. W. Barkema* \\ *Department of Production Animal Health, Faculty of Veterinary Medicine, University of Calgary, Calgary, AB, Canada, T2N 4N1 \\ †St. Anna Advies, 6525 Nijmegen, the Netherlands \\ ‡Department of Veterinary Clinical and Diagnostic Sciences, Faculty of Veterinary Medicine, University of Calgary, Calgary, AB, Canada, T2N 4N1
}

\section{ABSTRACT}

Implementation of specific management strategies on dairy farms is currently the most effective way to reduce the prevalence of Johne's disease (JD), an infectious chronic enteritis of ruminants caused by Mycobacterium avium subspecies paratuberculosis (MAP). However, dairy farmers often fail to implement recommended strategies. The objective of this study was to assess perceptions of farmers participating in a JD prevention and control program toward recommended practices, and explore factors that influence whether or not a farmer adopts risk-reducing measures for MAP transmission. Semi-structured interviews were conducted with 25 dairy farmers enrolled in a voluntary JD control program in Alberta, Canada. Principles of classical grounded theory were used for participant selection, interviewing, and data analysis. Additionally, demographic data and MAP infection status were collected and analyzed using quantitative questionnaires and the JD control program database. Farmers' perceptions were distinguished according to 2 main categories: first, their belief in the importance of JD, and second, their belief in recommended JD prevention and control strategies. Based on these categories, farmers were classified into 4 groups: proactivists, disillusionists, deniers, and unconcerned. The first 2 groups believed in the importance of JD, and proactivists and unconcerned believed in proposed JD prevention and control measures. Groups that regarded JD as important had better knowledge about best strategies to reduce MAP transmission and had more JD risk assessments conducted on their farm. Although not quantified, it also appeared that these groups had more JD prevention and control practices in place. However, often JD was not perceived as a problem in the herd and generally farmers did not regard JD control as a "hot topic" in communications with their herd veterinarian and other

Received January 13, 2016.

Accepted July 18, 2016.

${ }^{1}$ Corresponding author: cmnritte@ucalgary.ca farmers. Recommendations regarding how to communicate with farmers and motivate various groups of farmers according to their specific perceptions were provided to optimize adoption of JD prevention and control measures and thereby increase success of voluntary JD control programs.

Key words: behavior, attitude, mindset, biosecurity, cattle

\section{INTRODUCTION}

Johne's disease (JD) is an infectious enteritis of ruminants that is prevalent in most countries with a developed dairy industry. Infection with the bacterium causing JD, Mycobacterium avium ssp. paratuberculosis (MAP), can lead to substantial decreases in milk production, chronic diarrhea, and eventually death of affected cattle (Fecteau and Whitlock, 2010). In addition to well-documented effects of JD on animal health, productivity, and welfare, JD is also potentially linked to Crohn's disease in humans (Barkema et al., 2010). To reduce the prevalence and incidence of MAP infection and resultant economic losses for dairy farmers (Wolf et al., 2014b), many countries worldwide have implemented prevention and control programs for JD. One example of a voluntary JD program is the Alberta Johne's Disease Initiative (AJDI), launched in 2010 with the aim to reduce the estimated true herd-level MAP prevalence of $68 \%$ through farm-specific management changes (Wolf et al., 2014a).

Although a high level of participation is essential for infectious disease control programs to succeed (Barkema et al., 2014), often only a minority of farms enroll in voluntary programs for JD prevention and control (Hop et al., 2011; Nielsen, 2011). With approximately $65 \%$ enrollment of Alberta dairy farmers, participation in the AJDI was relatively high (notwithstanding, 35\% of farmers chose not to participate). Ritter et al. (2016) reported that MAP infection status did not differ among AJDI participants and nonparticipants. However, farmers not participating in the program were different from participating farmers in several aspects. 
In particular, they regarded available time as larger constraint on their farms and thought that costs associated with AJDI participation outweighed benefits (Ritter et al., 2015).

In addition to identifying impediments for enrollment of nonparticipants, it is also crucial to better understand participants' perceptions of voluntary programs such as the AJDI, given that its success is ultimately dependent on their continued participation and implementation of recommended management strategies for improved JD prevention and control. Uptake of suggested management changes to reduce MAP transmission was often reported to be $<50 \%$ (Wraight et al., 2000; Sorge et al., 2010; Wolf et al., 2015a), and many dairy farmers in Canada felt that there was no need to improve JD control on their farms (Sorge et al., 2010). Farmers participating in Ontario focus groups often did not perceive a recommendation as practical on their farm, whereas their veterinarians regarded the same recommendation as feasible and attainable (Roche, 2014).

Several studies have attempted to explain farmers' decision-making and farm management (e.g., Barkema et al., 1999; Jansen et al., 2009; Ellis-Iversen et al., 2010; Garforth, 2012; Roche, 2014). Important findings of these studies were that a broad variety of factors influenced farmers' behavior (e.g., on-farm resources such as available time or finances, farmers' knowledge of a certain matter, or their sense of responsibility for consumer health and safety). However, dairy farmers are by no means a homogeneous group (Gasson, 1973), and their behavior is influenced by their individual mindsets (i.e., a collection of unique psychological traits including perceptions, beliefs, attitudes, intentions, and skills; Jansen and Lam, 2012). Therefore, although the usefulness of psychological frameworks is indisputable to provide general factors that might influence people, it is also necessary to identify drivers of farmers' decision making and behavior and how those might differ among individuals.

Accordingly, the objective of this study was to gain an understanding of AJDI participants' mindset toward JD prevention and control. Farmers' experiences with the AJDI were explored, with special attention to their perceptions of recommended on-farm management strategies. A qualitative methodology (grounded theory) was chosen. In grounded theory, data are used to generate patterns within the data without testing a specific a priori hypothesis (Glaser and Strauss, 1967). Constant comparison of emerging concepts and their describing subcategories is used to develop a theory that aims to explain why people make certain decisions. This approach allowed us to inductively obtain an understanding of farmers' perceptions without imposing their responses through predefined choices. Based on the findings, recommendations for successful communication with participating farmers were provided to improve on-farm JD prevention and control.

\section{MATERIALS AND METHODS}

\section{Selection of Farmers}

Dairy farmers participating in the AJDI were eligible for the study. Participation in the program consists of on-farm assessments, during which an AJDI-trained veterinarian identifies high-risk areas for MAP transmission and provides recommendations to mitigate risk (Wolf et al., 2014a). The risk assessment and management plan (RAMP) is combined with environmental fecal sampling to determine the farm's MAP infection status (Wolf et al., 2014a,b). Because of the voluntary nature of the AJDI, farmers can choose whether or not they want to repeat RAMP administration and fecal testing annually. In the present study, a farmer was defined as an AJDI participant if $\mathrm{s} /$ he had at least one RAMP and environmental fecal testing done since program implementation.

Purposive sampling was used for selection of farmers to capture a variety of different perspectives. In that regard, farmers' statements from conducted interviews guided selection of consecutive participants (e.g., toward the end of the study, efforts were made to primarily recruit participants with MAP-positive test results to obtain more information on the perceived effect of JD on their farm). Another criterion was to select farmers from various geographic regions at a feasible driving distance (maximally $600-\mathrm{km}$ round trip) from Calgary, Alberta, Canada. Selected farmers were contacted by telephone and asked to participate in the study. Of the 30 contacted farmers, $25(83 \%)$ agreed to be interviewed, and a meeting on their farm was scheduled. Reasons to refuse interviewing were no interest $(\mathrm{n}=2)$, no time $(\mathrm{n}=2)$, or the producer had ceased dairy farming $(\mathrm{n}=1)$. Interviews were done between November 2014 and July 2015.

\section{Data Collection}

The interview process was based on the methodology of classical grounded theory (Glaser and Strauss, 1967). The first 10 interviews were conducted separately, with transcription and coding done after every interview to identify emerging themes and adjust subsequent interviews according to farmers' statements. Afterward, to enhance study feasibility, 2 interviews at a time were scheduled on 4 different days, with transcription and coding done between days. The last 7 interviews were 
conducted on 2 different days (with 3 and 4 interviews per day, respectively). No more interviews were scheduled when additional farm visits did not generate important new data (i.e., theoretical saturation was achieved).

During the early stages of the study, a last-year DVM student (third author) conducted 5 interviews. The rationale for that decision was to interview farmers by someone with knowledge of dairy farming but with limited background of the social-psychological factors that influence farmers' decision-making, and therefore reduce bias that could arise by existing preconceptions. This approach was chosen to obtain a broad spectrum of themes. Emerging themes were explored in subsequent interviews conducted by the first author (DVM, $\mathrm{PhD}$ student).

The interviews were audio-recorded, and a semistructured interview pattern was used. The interviewer initially asked broad open-ended questions about the farm as an operation, the farmer's perceptions toward JD, and about suggested management changes. Although the farmer was encouraged to guide the conversation, for clarification, or to obtain more information, the interviewer could ask follow-up questions on a specific subject raised by the farmer. A question guide, which was continuously adjusted based on previous interviews, was used to facilitate the interview process (Appendix Table A1).

After every audio-recorded interview, the farmer was asked to complete a short paper-based questionnaire consisting of 9 questions on demographical data (e.g., age and education of the farmer, herd size, current bulk tank SCC, and daily milk production of the herd). Completion of the questionnaire took on average $3 \mathrm{~min}$. Additionally, information on total number of conducted risk assessments and results of environmental fecal MAP testing were derived from the AJDI database and used for analysis.

\section{Data Analysis}

Quantitative Analysis. Data from the questionnaire and the AJDI database were used for descriptive statistics. For continuous variables, mean and median was assessed, whereas for yes/no questions, number and percentage of affirmative answers was compiled. Differences between farmer groups in regard to continuous variables were assessed using Student's $t$-test. Questions requiring yes/no answers were analyzed using a 2 -sample test of proportions. A $P$-value $<0.05$ was considered statistically significant.

Qualitative Analysis. Audio-recorded interviews were transcribed in full and coded by the first author using specialized software (ATLAS.ti Scientific Software
Development, Berlin, Germany). First, open coding was used by assigning in vivo codes (i.e., distinct words that the participant used and that describe an incident well) or label codes (i.e., summaries of a particular incident) to text passages. Second, after identification of the basic social process, coding was limited to codes that related to the identified process (Glaser, 1978). Third, theoretical coding was used explore how identified codes are linked to each other. These relations are used to connect discrete categories into concepts and eventually into a theory (Glaser, 1978).

At any stage of interviewing, transcription, or coding, memos (i.e., notes) were written to promote the subsequent development of the theory (Chenitz and Swanson, 1986). Additionally, systematic re-evaluation ensured relevance of coded units and identified inter-relations between codes (Goulding, 2002). No formal reliability test was conducted; however, authors frequently consulted with each other (and other researchers) over the course of the study to review the face validity of emerging themes.

\section{RESULTS}

\section{Descriptive Statistics}

Twenty-two of the interviews were done with only one person (one of them was a female farmer), 2 interviews were conducted with 2 male farmers, and one was conducted with a family (husband, wife, and daughter). All interviewed participants were largely involved in management decisions. Farmers filling out the questionnaire were on average $45 \mathrm{yr}$ old (median $=45$; Table 1), and had on average 151 lactating cows (median = $125)$ with an average daily milk production of $33 \mathrm{~kg}$ per cow $($ median $=34)$. Most farmers used milk recording systems $(80 \%)$, had at least one veterinary herd health visit per month $(76 \%)$, and had purchased cattle in the last 5 yr $(68 \%)$.

\section{Identified Categories and Subcategories of the Qualitative Analysis}

Perceptions of farmers interviewed together did not differ, and their responses were treated as if they were derived from only one person. Two main categories were distinguished that described farmers' perceptions toward JD and its prevention and control, namely JD importance to the farmer and the farmer's belief in proposed strategies to prevent or control this disease. The 2 main categories consisted of different themes (i.e., subcategories; Table 2). Every farmer's perceptions toward each of the subcategories were rated as positive, negative, or neutral. The latter was assigned 
IMPLEMENTATION OF JOHNE'S DISEASE CONTROL

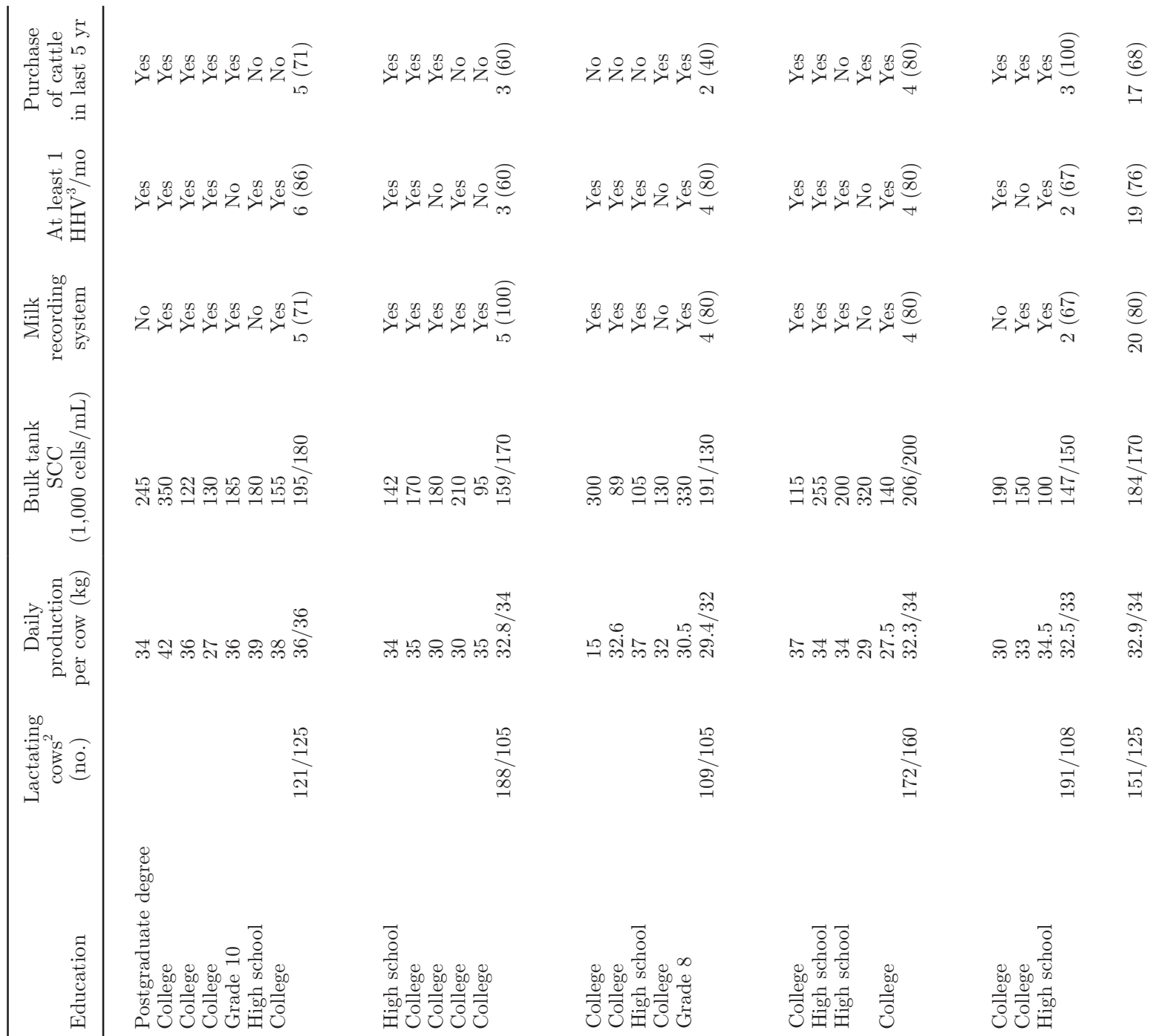

范

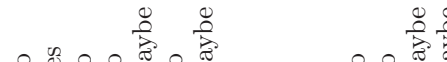

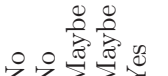

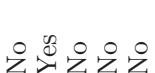

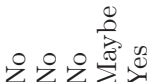

象足:
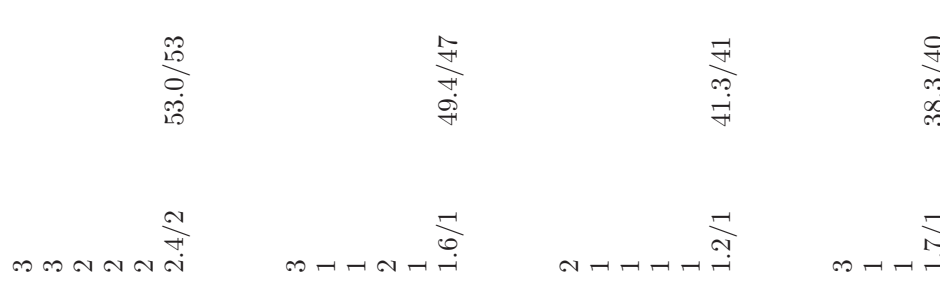

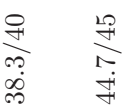

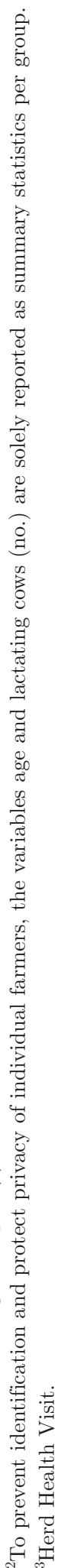


Table 2. Examples of positive and negative statements made by Alberta Johne's Disease Initiative (AJDI) participants toward the subcategories comprising the 2 main categories: importance of Johne's disease (JD) and farmers' belief in proposed JD prevention and control strategies

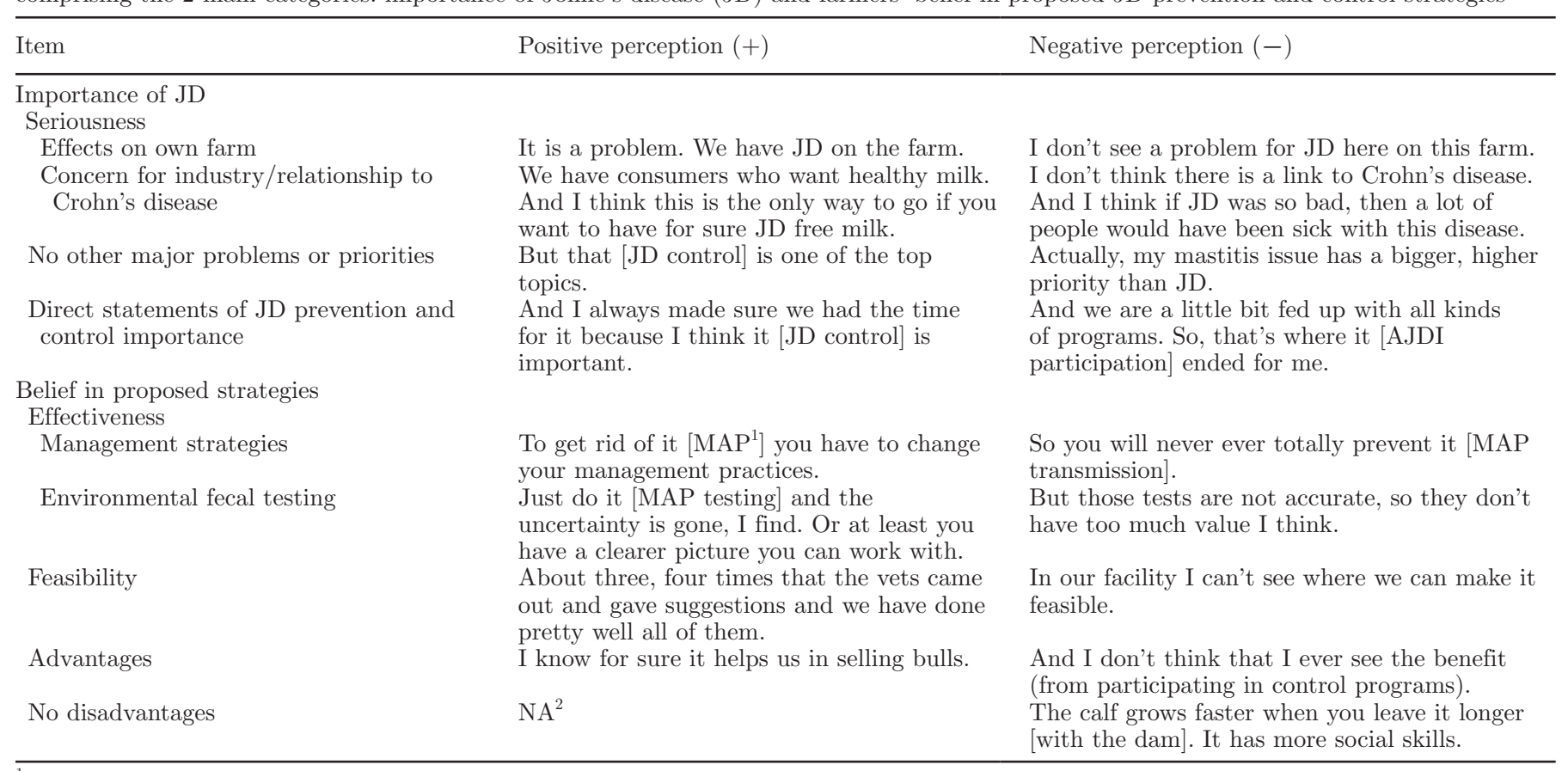

${ }^{1} \mathrm{MAP}=$ Mycobacterium avium subspecies paratuberculosis.

${ }^{2}$ Not applicable: no farmer mentioned that JD prevention and control has no disadvantages.

if the farmer either had a neutral opinion (e.g., was unsure if there is a link between JD and Crohn's disease) or provided equally positive and negative statements. Additionally, farmers' direct statements regarding importance of JD were taken into account.

(1) Importance of JD Prevention and Control. This category had 2 distinct subcategories:

(a) Seriousness of JD. The perceived seriousness of JD depended on 2 factors: (1) effect of JD on the producer's operation, and (2) role of JD with regards to consumer safety and the dairy industry. Farmers regarded JD control as more important if they felt the disease had a limiting effect on farm economics, animal health or welfare. The potential for a link between JD and Crohn's disease was for some farmers a reason to take JD more seriously, whereas others did not believe in a link or did not regard it as their responsibility to mitigate risk.

(b) Other major problems or priorities. If farmers struggled with general farm chores (e.g., milking, harvesting), herd performance (e.g., fertility), or other cattle diseases (e.g., mastitis), JD management was often regarded as being less important. Conversely, farmers that did not have other major concerns on their farm could allocate more resources (e.g., time or money) to JD prevention and control.

(2) Belief in Proposed Strategies for JD Control and Prevention. This category was composed of 3 distinct subcategories:

(a) Belief in effectiveness. Farmers differed in their perception about whether proposed management strategies were efficient in preventing introduction of MAP or its reduction on the farm. Also, some farmers regarded environmental fecal testing as an essential tool, whereas others did not believe the test helped them to prevent or control JD.

(b) Feasibility. Even farmers that regarded a recommended management strategy as generally effective could perceive that particular suggestion as not feasible on their farm, due to farm-specific limitations.

(c) Weighing advantages and disadvantages. Whereas some farmers recognized advantages of proposed management strategies beyond improved JD control (e.g., reduced incidence of other calf diseases), perceived disadvantages of JD control were often also taken into consideration when deciding on JD prevention and control strate- 
gies for the farm (e.g., reduced colostrum quality after pasteurization).

Based on their ratings in subcategories, each farmer was classified as having a positive $(+)$, negative $(-)$, or neutral (0) perception toward the 2 main categories (Table 3). If a farmer did not express an opinion regarding one of the subcategories, that subcategory was not used for classification of this farmer. According to the 2 main categories, 22 farmers were categorized into 4 distinct groups (Figure 1). In addition, 3 farmers had a neutral perception to at least one of the main categories and therefore could not unambiguously be assigned to a group.

\section{Identified Farmer Groups}

Proactivists. Farmers in this group believed that JD prevention and control were important and should be pursued. In addition to their sense of accountability toward their animals' health and welfare, they acknowledged their responsibility for consumer health and the dairy industry. One farmer said: "So many things get misrepresented in the media anyways, so we want to make sure that there can be no doubt, we better eliminate JD as much as we can, so we don't even get into that discussion." All proactivists tried to stay on top of things and were well informed. They implemented all or most of the recommended JD prevention and control strategies. If farm-specific resources did not immediately allow for a modification, these farmers implemented the recommendations when their situation changed (e.g., when they could afford to modify the barn). Although 3 of 7 farmers in this group only had one RAMP done, they attempted to maintain a high standard or even further improve their JD prevention and control measures, independent of the AJDI. These farmers reasoned that they did not conduct a follow-up because their farms were tested MAPnegative and their first assessment did not reveal any substantial risks for MAP transmission. Besides their belief in its effectiveness, proactivists also recognized the advantages of JD control; points mentioned were that it improved cows' sustainability and welfare, and that many strategies for JD control were also beneficial in controlling other cattle diseases. Two of 5 farmers in this group with negative MAP test results participated in a certification program for herds that are likely JD free. One of them said: "I think it helps us for sales, so it is important to keep that status. We have to compete with a lot of farms." However, both farmers also stated that the vast majority of buyers did not ask for the JD certification.
Disillusionists. Similar to proactivists, disillusionists believed in the importance of JD prevention and control. Although uncertain about a potential link to Crohn's disease, one of them said, "And even if it's not linked, if we can do better for our cows, for the future of the herd." However, in contrast to proactivists, they often saw disadvantages in a range of management practices due to perceived negative effects on animal welfare, health, or production. Examples included immediate separation of newborn calf and dam ("there is a lot of good stuff in licking the calf"), or having separate calving pens ("the nature of the cow is that she wants to be together"). One farmer even said, "And now the farmer has to make the choice: Go for JD or go for animal welfare?"

Disillusionists were interested in available research, although 3 of them remarked that they did not receive satisfactory information on research outcomes to guide their management decisions. Farmers in this group were skeptical regarding efficiency of management strategies and testing for JD disease. They especially criticized the lack of test sensitivity and questioned how an inaccurate test would benefit their JD control efforts: "How do you control JD if you can't check?" Lack of commitment from the veterinarian or other farmers was also a source of frustration. One farmer said, "And nobody does it, so why would I do it? My milk gets punched in the same tank as my neighbors. So, doesn't make sense for me to put extra money in [JD control]." All disillusionists were well informed about general management strategies to reduce JD, but often criticized the feasibility of suggested measures. However, they generally tried to minimize the risk of MAP transmission and all of them had several proposed management strategies in place.

Unconcerned. Farmers in this group did not regard JD prevention and control as their priority. They did not contemplate potential management changes on their farm in detail, and only 2 farmers were well informed about general practices to reduce MAP transmission. Members in this group often mentioned that they enrolled in the AJDI because it was a free-of-cost opportunity to assess MAP infection status of their herd without being too concerned about a potential link to Crohn's disease. Although they acknowledged the usefulness of the recommended management strategies provided, and liked the concept of the AJDI, they did not feel the urgency to actually make a change: "He [the veterinarian] really made his point and we wrote it all down what I was gonna do. And, uh, my follow-up was a bit poor, I think." Even farmers in this group that sporadically had clinical cases currently did not perceive JD as a problem in the herd. One of 
RITTER ET AL.

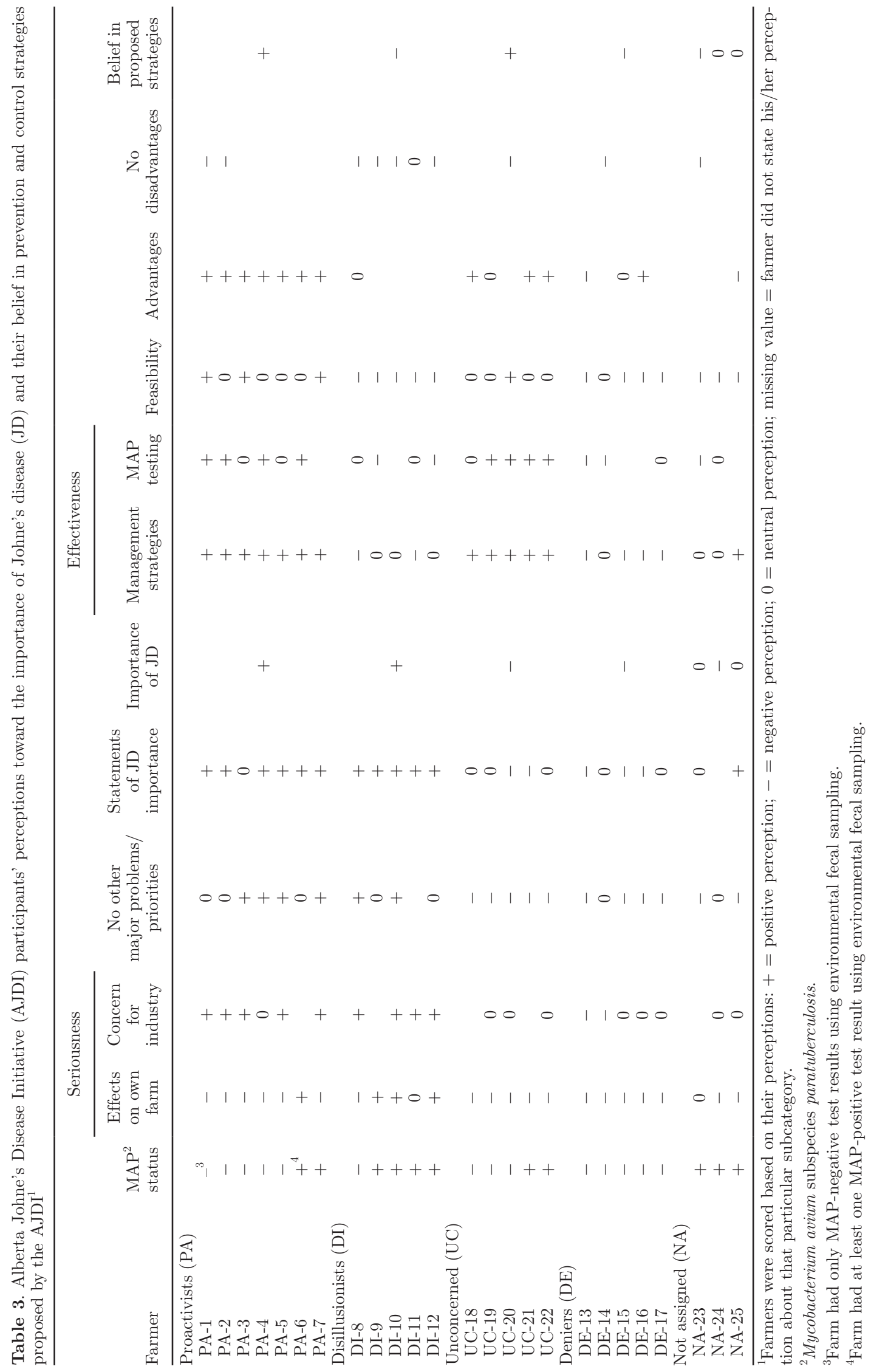




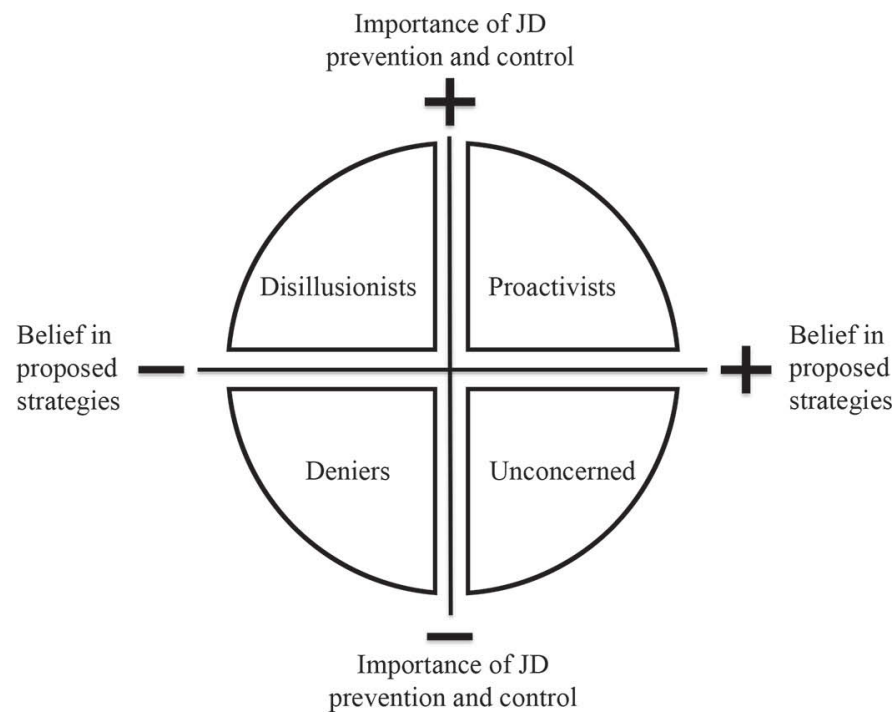

Figure 1. Grouping of Alberta Johne's Disease Initiative participants according to their perceptions toward the importance of Johne's disease (JD) and their belief in the strategies proposed for its prevention and control.

them stated, "It probably all depends on the amount of JD that's there, and since it's limited, you are not as motivated to change things." The unconcerned had aspirations other than JD prevention and control. One of them explained, "With a new barn you can't start too many things at once." Two of the farmers in this group hardly had any strategies in place to prevent or control JD, whereas the remaining 3 farmers had implemented a few of the recommended strategies.

Deniers. Deniers did not recognize the importance of JD prevention and control and often had other priorities on their farm. Two of them were well informed about best management practices to reduce MAP transmission, and 2 of the 5 farmers in this group had made efforts to implement some of the recommended strategies. Despite MAP-positive test results, the affected farmers felt that they could manage the disease with culling. Three of the 5 deniers expressed some frustration with the industries' and governments' approach to cattle disease control. One of them stated: "[The industry] is pushing down programs, too. That cost us a lot of money. And I don't think that I ever see the benefit." Although they did not necessarily exclude a potential link to Crohn's disease, they were not concerned about the connection: "With everything there is a risk, even with eating food." Deniers often enrolled in the AJDI because their veterinarian urged them to participate and it did not cost them anything. Four of 5 farmers in this group only had one risk assessment done and regarded it as impossible to improve their management in their current facility and therefore reduce MAP prevalence. They also felt that the risk of (re-) infecting the herd through feed or roaming wildlife was very high, and therefore did not see how it would be possible to permanently eradicate the disease.

\section{Additional Observations}

All farmers had a (very) good relationship with their herd veterinarian. However, only 2 farmers stated that JD was often brought up with their veterinarian or other farmers. One producer summarized that JD was not a "hot topic" among farmers anymore and 2 others stated that JD was even regarded by some as "taboo topic," and that those farmers were unwilling to talk about the status of their farm or problems they might have with JD. Although infection status of the farm (MAP +/-) influenced the importance farmers attributed to JD control, it did not appear to be the only determinant of the number of adopted management practices. Knowledge about general recommendations for best JD prevention and control practices varied among groups, but each farmer was aware of at least some recommendations (often ones made in the risk assessment). Also, although it was not an interview topic, 10 farmers across all groups indicated that they would like to learn more about MAP transmission and JD status on a provincial scale.

Statistical analyses were limited due to the small sample size. The only difference between groups was that farmers regarding JD control as important had, on average, more than 2 RAMP done (mean: proactivists $=2.1$, disillusionists $=2.4)$. This was different $(P=$ 0.03 ) from the 2 groups that did not see JD control as important and had less than 2 RAMP done (mean: deniers $=1.2$, unconcerned $=1.6)$. Although not statistically significant $(P=0.07)$, proactivists tended to have a higher average milk production (36 kg per cow/d) compared with other farmers, which had average daily milk productions of $32.8,29.4$, and $32.3 \mathrm{~kg}$ per cow $/ \mathrm{d}$ (disillusionists, unconcerned, and deniers, respectively).

\section{DISCUSSION}

Results of this study were supported by the psychological framework of the health belief model (Rosenstock, 1974; Janz and Becker, 1984; Figure 2). According to this model, a combination of factors is needed to elicit change. In this study, farmers not only needed to perceive JD as a serious threat for their farm, the industry, or both to acknowledge its importance, they also needed to believe in proposed management solutions to be proactive.

Unfavorable perceptions about the disease and its prevention and control, rather than a lack of knowl- 
edge, appeared to be primary barriers to implement recommended measures. Therefore, extension efforts should not only inform farmers about technical aspects of JD control but should also aim to positively influence farmers' perceptions about the importance and proposed strategies. National or provincial extension tools (e.g., newsletters) are certainly important to reach a large number of producers with information about provincial JD status, latest research, or recommended management strategies; however, because of their familiarity with farm and farmer, veterinarians are in an ideal position to assess farmers' individual perceptions, attitudes, and beliefs (Ellis-Iverson et al., 2010). General questions that can be asked by herd veterinarians to assess farmers' hesitation to implement changes (e.g., building individual calving pens) include, "What do you think about [individual calving pens]?" or "What is your view on [individual calving pens]?" Knowing in which group a farmer belongs will help veterinarians to adjust their communications accordingly. The following paragraphs offer some suggestions of how the authors believe different farmer groups can be targeted more effectively.

It is important to keep proactivists informed and interested to ensure continuous engagement in JD management strategies. Besides educating them about newest developments in research and industry, discussion groups can be an effective way to allow proactivists to self-directedly talk about their topics of interest. If a particular recommendation is temporarily regarded as not feasible, veterinary practitioners should ensure that the issue is brought forward again when the on-farm situation changes (e.g., when more money or personnel become available). Offering a certification program for negative herds can be a good incentive for proactivists to maintain their negative status or strive for MAP reduction.

Disillusionists are in a state of cognitive dissonance (Festinger, 1957); therefore, although they are motivated to combat JD, they are hesitant to fully commit to it due to their doubt in proposed management strategies. However, according to the theory of cognitive dissonance, people try to establish internal consistency among their perceptions, values, attitudes as well as their behavior. Consequently, veterinarians should encourage farmers that fall into this group to overcome their ambiguity and increase their trust in recommended strategies. For example, they should be informed that similar JD control programs were successful in decreasing within-herd MAP prevalence (Collins et al., 2010; Sorge et al., 2011). If they see more disadvantages in a management change than advantages (e.g., reduced animal welfare by having separate calving pens), veterinarians should work at a compromise that might not be optimal for JD control but will more likely be implemented (e.g., group pens that are cleaned more often). Having facilitated discussion groups might reduce farmers' doubts, especially if proactivists are present that can share their experiences and motivate uptake of recommended measures.

Many unconcerned farmers did not consider JD as important enough to invest in its control. One reason for this perception was that few farmers regarded JD as a problem on their farm, even if they had received MAP-positive test results or observed clinical JD cases. Therefore, changing this perception is key to implementing change. The normative frame of reference (i.e., at what point does a farmer believe a disease is a problem for the herd) has been demonstrated to influence farmers' motivation to take action and explained a substantial part in the variance of disease incidence (Jansen et al., 2009). To change farmers' normative frame of reference with regards to JD, farmers should be made aware that for every cow with clinical JD, there are likely 15 to 25 subclinically infected cows in the herd (Fecteau and Whitlock, 2010). Furthermore, the potentially negative economic effect of JD on the dairy operation through (sub-) clinically infected ani-

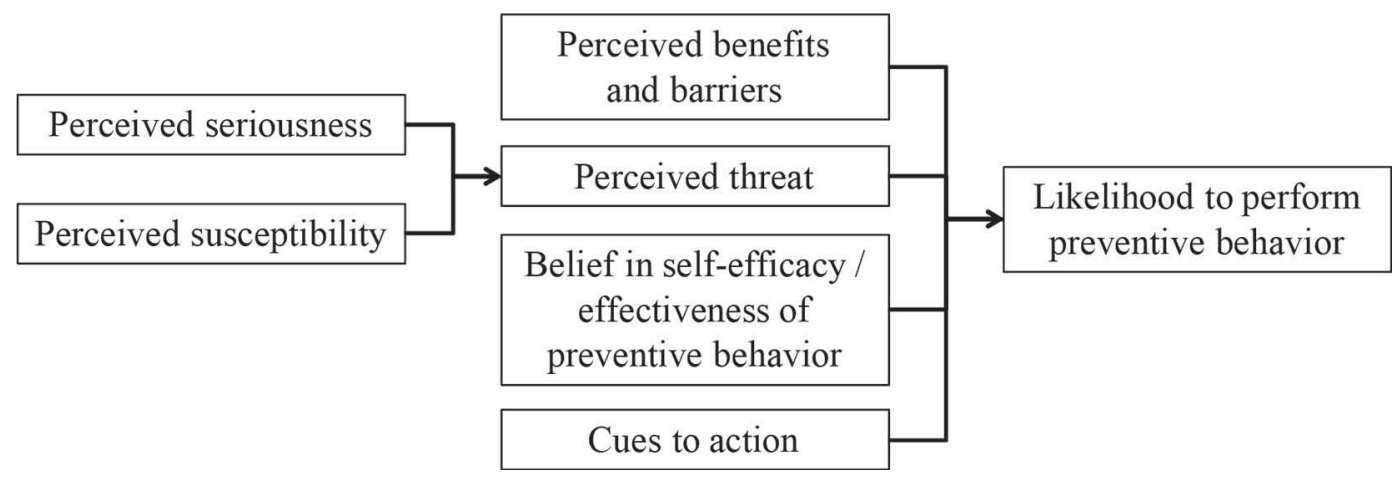

Figure 2. Psychological framework of the health belief model (modified from Jansen and Lam, 2012). 
mals should be highlighted (McKenna et al., 2006; Wolf et al., 2014b).

Because of their negative perceptions toward both categories, it will likely be most difficult to motivate deniers to adopt JD control strategies. Veterinarians need to combine communication strategies outlined for disillusionists and unconcerned. However, potentially only external regulations [e.g., (financial) penalties or incentives] will be effective in motivating on-farm changes in this group.

It is important to realize that farmers can move through the model in time as circumstances change (e.g., financial resources or time availability). Therefore, veterinarians should assess farmers' perceptions in regard to JD on a regular basis. If the farmer has temporarily a different priority than JD control (e.g., a mastitis outbreak) veterinarians should support farmers in combating the urgent issue first while encouraging the farmer to maintain JD control measures that have been already in place.

Dutch farmers classified by their veterinarians as hard to reach with information on mastitis had similarities with the 4 groups identified in the current study (Jansen et al., 2010). Disillusionists questioned the information they received, similar to the do-it-yourselfers that lacked trust in external information sources (Jansen et al., 2010). Deniers (similar to reclusive traditionalists) were critical toward disease control programs on a provincial or national level. The unconcerned lacked a sense of urgency to take action, similar to the waitand-seers identified by Jansen and colleagues. In both studies, proactivists were well informed and recognized that the importance of disease control extended well beyond their own farm. This indicates that, although the studies differed in geographical location, subject, and farmer characteristics (hard-to-reach versus voluntary participants), farmers could be characterized by some universal traits. However, in a consecutive quantitative study, Derks et al. (2013) could not confirm the groups identified by Jansen et al. (2010). Different methods (i.e., qualitative semi-structured interviews versus quantitative postal surveys), different time periods, and interviewed farmers might come to divergent conclusions without one study being more valid than the other.

Purposive sampling and continuation of interviewing until theoretical saturation was achieved aimed to reduce the risk of missing relevant (sub-) categories. However, quantitative methods with larger sample sizes will be used to evaluate generated hypotheses of the current exploratory study while being open-minded to other potential influences on farmers' decision making. Due to purposive sampling, this study cannot claim to describe a representative distribution of farmers among the 4 groups. This question, as well as whether farmers with common perceptions have similar behaviors, will be assessed quantitatively using a random sample of farms.

In this study, farmers had a mean of 151 lactating cows and 11/25 (44\%) of farms were MAP infected. These findings were similar to results from previous studies that included all AJDI participants and reported a mean of 139 lactating cows and a province-wide observed MAP prevalence of 47\% (Wolf et al., 2014a, 2015a). Also, AJDI participants sampled for another recent study had demographic characteristics similar to farms included in the current study, with a median bulk tank SCC of 160,000 cells/mL and a median daily milk yield of $33 \mathrm{~kg} / \mathrm{cow}$ (Ritter et al., 2015). Therefore, we expect that our findings resonate provincially and potentially internationally.

Correlation between the 2 main categories is possible (e.g., farmers that do not believe in proposed measures regard the problem as less relevant; Jansen and Lam, 2012). However, a quantitative survey including several questions addressing both categories was conducted with 61 AJDI participants (Ritter et al., 2015), and only a weak correlation was found between categories (Pearson correlation coefficient: 0.28; unpublished data).

The adjustment of questions according to previous interviews is a method used in grounded theory (Glaser and Strauss, 1967). In this study, adjusting questions over the course of the data collection phase resulted in obtaining different depth of information from the farmers regarding each of the subcategories. Classification of the farmers into the 4 groups was only based on the information obtained. However, we believe that this did not bias the results because (1) per farmer, there was never more than 1 or 2 subcategories without any information regarding the perceived importance of JD and the belief in proposed strategies, respectively; and (2) initially, we always asked broad questions and let the farmers guide the conversation; more specific questions (e.g., regarding the potential link to Crohn's disease) were asked at the end of the interview if not already brought up by the farmer. The possibility that farmers would give socially desirable answers could have led to bias. In this case, we would expect farmers' perceptions toward JD prevention and control to be more negative than assessed in the study.

Qualitative interviews were used to gain a general impression of the farmers' adoption of strategies. Exact quantification of implemented changes would have provided more detail to the study. However, AJDI risk assessments did not show whether a specific recommendation from a previous year (if the farmer had more than one RAMP done) had been implemented, 
but rather provided risk assessment scores for specific categories (Wolf et al., 2015a).

\section{CONCLUSIONS}

Although most dairy farmers did not perceive JD as a current problem on their farm, they differed in their perceptions of the disease importance and their beliefs regarding proposed prevention and control strategies. If unfavorable, these perceptions, and not a lack of knowledge, inhibited implementation of recommended strategies to improve JD management. Therefore, it is recommended that veterinary practitioners should have a key role in exploring farmers' individual reasons for not adopting best JD management practices and work toward feasible solutions.

\section{ACKNOWLEDGMENTS}

This study was funded by Alberta Milk (Edmonton, AB, Canada), the Alberta Livestock and Meat Agency Ltd. (Edmonton, AB, Canada), and Canada's Natural Sciences and Engineering Research Council (NSERC) Industrial Research Chair Program with industry contributions from Alberta Milk, the Dairy Farmers of Canada (Ottawa, ON, Canada), Dairy Farmers of Manitoba (Winnipeg, MB, Canada), British Columbia Dairy Association (Burnaby, BC Canada), Westgen Endowment Fund (Milner, BC, Canada), Canadian Dairy Network (Guelph, ON, Canada), and CanWest DHI (Guelph, ON, Canada).

\section{REFERENCES}

Barkema, H. W., S. Hendrick, J. de Buck, G. G. Kaplan, and K. Rioux. 2010. Crohn's disease in humans and Johne's disease in cattle-Linked diseases? Pages 197-213 in Zoonotic Pathogens in the Food Chain. Ed. D. Krause and S. Hendrick. CAB International, Wallingford, UK.

Barkema, H. W., K. Orsel, A. Koets, V. P. Rutten, J. Bannantine, G. P. Keefe, D. F. Kelton, S. J. Wells, R. Whittington, C. G. Mackintosh, E. J. Manning, M. F. Weber, J. P. Kastelic, and J. De Buck. 2014. Bottlenecks in the prevention and control of Mycobacterium avium ssp. paratuberculosis infection. Pages 111-113 in Proc. 12th Int. Colloq. Paratuberculosis, Parma, Italy.

Barkema, H. W., J. D. van der Ploeg, Y. H. Schukken, T. J. G. M. Lam, G. Benedictus, and A. Brand. 1999. Management style and its association with bulk milk somatic cell count and incidence rate of clinical mastitis. J. Dairy Sci. 82:1655-1663.

Chenitz, C., and C. Swanson. 1986. From Practice to Grounded Theory: Qualitative Research in Nursing. Addison-Wesley, Menlo Park, CA.

Collins, M. T., V. Eggleston, and E. J. Manning. 2010. Successful control of Johne's disease in nine dairy herds: Results of a six-year field trial. J. Dairy Sci. 93:1638-1643.

Derks, M., T. van Werven, H. Hogeveen, and W. D. J. Kremer. 2013. Veterinary herd health management programs on dairy farms in the Netherlands: Use, execution, and relations to farmer characteristics. J. Dairy Sci. 96:1623-1637.
Ellis-Iversen, J., A. J. C. Cook, E. Watson, M. Nielen, L. Larkin, M. Wooldridge, and H. Hogeveen. 2010. Perceptions, circumstances and motivators that influence implementation of zoonotic control programs on cattle farms. Prev. Vet. Med. 93:276-285.

Fecteau, M. E., and R. H. Whitlock. 2010. Paratuberculosis in cattle. Pages 144-156 in Paratuberculosis: Organism, Disease, Control. CABI, Wallingford, UK.

Festinger, L. 1957. A Theory of Cognitive Dissonance. Stanford University Press, Stanford, CA

Garforth, C. J. 2012. Effective communication to improve udder health: Can social science help? Pages 55-66 in Udder Health and Communication. H. Hogeveen and T. J. G. M. Lam, ed. Wageningen Academic Publishers, Wageningen, the Netherlands.

Gasson, R. 1973. Goals and values of farmers. J. Agric. Econ. 24:521542 .

Glaser, B. G. 1978. Theoretical Sensitivity: Advances in the Methodology of Grounded Theory. Sociology Press, Mill Valley, CA.

Glaser, B. G., and A. L. Strauss. 1967. The Discovery of Grounded Theory: Strategies for Qualitative Research. Aldine, Chicago, IL.

Goulding, C. 2002. Grounded Theory: A Practical Guide for Management, Business and Market Resource. Sage, Thousand Oaks, CA.

Hop, G. E., A. G. J. Velthuis, and K. Frankena. 2011. Assessing Dutch farmers' incentives to join a voluntary Johne's disease programme. NJAS-Wagen. J. Life Sci. 58:57-64.

Jansen, J., and T. J. G. M. Lam. 2012. The role of communication in improving udder health. Vet. Clin. North Am. Food Anim. Pract. $28: 363-379$.

Jansen, J., C. D. M. Steuten, R. J. Renes, N. Aarts, and T. J. G. M. Lam. 2010. Debunking the myth of the hard-to-reach farmer: Effective communication on udder health. J. Dairy Sci. 93:1296-1306.

Jansen, J., B. H. P. Van den Borne, R. J. Renes, G. Van Schaik, T. J. G. M. Lam, and C. Leeuwis. 2009. Explaining mastitis incidence in Dutch dairy farming: The influence of farmers' attitudes and behaviour. Prev. Vet. Med. 92:210-223.

Janz, N., and M. H. Becker. 1984. The health belief model: A decade later. Health Educ. Q. 11:1-47.

McKenna, S. L. B., G. P. Keefe, A. Tiwari, J. VanLeeuwen, and H. W. Barkema. 2006. Johne's disease in Canada. Part II. Disease impacts, risk factors, and control programs for dairy producers. Can. Vet. J. 47:1089-1099.

Nielsen, S. S. 2011. Dairy farmers' reasons for participation in the Danish control programme on bovine paratuberculosis. Prev. Vet. Med. 98:279-283.

Ritter, C., G. P. S. Kwong, R. Wolf, C. Pickel, M. Slomp, J. Flaig, S. Mason, C. L. Adams, D. F. Kelton, J. Jansen, J. De Buck, and H. W. Barkema. 2015. Factors associated with participation of Alberta dairy farmers in a voluntary, management-based Johne's disease control program. J. Dairy Sci. 98:7831-7845.

Ritter, C., R. Wolf, C. L. Adams, D. F. Kelton, C. Pickel, S. Mason, K. Orsel, J. De Buck, and H. W. Barkema. 2016. Short communication: Herd-level prevalence of Mycobacterium avium subspecies paratuberculosis is not associated with participation in a voluntary Alberta Johne's disease control program. J. Dairy Sci. 99:21572160.

Roche, S. 2014. PhD thesis: Investigating the role of agricultural extension in influencing Ontario dairy producer behaviour for Johne's disease control. University of Guelph, Guelph, Canada.

Rosenstock, I. 1974. Historical origins of the health belief model Health Educ. Behav. 2:328-335.

Sorge, U., D. Kelton, K. Lissemore, A. Godkin, S. Hendrick, and S. Wells. 2010. Attitudes of Canadian dairy farmers toward a voluntary Johne's disease control program. J. Dairy Sci. 93:1491-1499.

Sorge, U. S., K. Lissemore, A. Godkin, J. Jansen, S. Hendrick, S. Wells, and D. F. Kelton. 2011. Changes in management practices and apparent prevalence on Canadian dairy farms participating in a voluntary risk assessment-based Johne's disease control program. J. Dairy Sci. 94:5227-5237.

Wolf, R., H. W. Barkema, J. De Buck, and K. Orsel. 2015a. Factors impacting management changes on farms participating in a Johne's disease control program. J. Dairy Sci. 98:7784-7796. 
Wolf, R., H. W. Barkema, J. De Buck, and K. Orsel. 2015b. Sampling location, herd size and season influence Mycobacterium avium ssp. paratuberculosis environmental culture results. J. Dairy Sci. 98:275-287.

Wolf, R., H. W. Barkema, J. De Buck, M. Slomp, J. Flaig, D. Haupstein, C. Pickel, and K. Orsel. 2014a. High herd-level prevalence of Mycobacterium avium subspecies paratuberculosis in Western Canadian dairy farms, based on environmental sampling. J. Dairy Sci. 97:6250-6259.
Wolf, R., F. Clement, H. W. Barkema, and K. Orsel. 2014b. Economic evaluation of participation in a voluntary Johne's disease prevention and control program from a farmer's perspective- The Alberta Johne's Disease Initiative. J. Dairy Sci. 97:2822-2834.

Wraight, M. D., J. McNeil, D. S. Beggs, R. K. Greenall, T. B. Humphris, R. J. Irwin, S. P. Jagoe, A. Jemmeson, W. F. Morgan, P. Brightling, G. A. Anderson, and P. D. Mansell. 2000. Compliance of Victorian dairy farmers with current calf rearing recommendations for control of Johne's disease. Vet. Microbiol. 77:429-442.

\section{APPENDIX}

Table A1. Question guide used to interview farmers participating in the Alberta Johne's Disease Initiative (AJDI)

General questions

Please describe your farm.

What comes to mind when you think about $\mathrm{JD}^{2}$ ?

To what extent is JD a problem for you?

How do you try to prevent JD transmission?

What is your impression about JD issues and control on other farms?

Tell me about your experience with the AJDI.

How would you describe your relationship with your veterinarian?

Could you describe how you came up with the management recommendations made in the risk assessment?

What do you think of the management changes the veterinarian suggested?

Do you think there is a connection between JD and Crohn's disease? $^{1}$

Do you have anything to add?

\footnotetext{
${ }^{1}$ Question was added during the course of the study.

${ }^{2} \mathrm{JD}=$ Johne's disease.

${ }^{3} \mathrm{MAP}=$ Mycobacterium avium subspecies paratuberculosis.
}

Probing questions

- How would you describe the general performance of your farm?

- What are the largest goals and constraints on your farm?

- Would you do anything differently if you could re-build this barn? ${ }^{1}$

- What are your plans for the future? ${ }^{1}$

- Do you have JD on your farm?

- Is there anything that worries you about JD?

- What measures do you have in place to prevent JD transmission within the farm and introduction onto the farm?

- What do you think about your efforts to prevent JD transmission?

- What do other farmers do/think about JD control?

- In relation to others - do you think you are doing a good job to reduce JD on your farm?

- Why did you decide to participate?

- What did you like? What did you not like?

- Is there anything about the AJDI that could be improved?

- In what situations do you call the veterinarian on your farm?

- How often and in what ways do you communicate with your veterinarian?

- Is there anything that could be improved in your communication or relationship with the veterinarian?

- What does your veterinarian say about JD and the AJDI?

- Where/when did you talk about the management changes?

- How did the veterinarian support you with the implementation of the changes?

- Did the veterinarian follow up on the recommendations from the previous year?

- What do you think is important to consider when coming up with a management strategy?

- Do you feel the recommendations make sense?

- What did you like/not like about the recommendations?

- At the time of the risk assessment how did you feel about the management changes then? Were you confident you would implement them?

- What influences whether you implement a change or not?

- Have you changed anything that is not mentioned in the risk assessment?

- Would you do anything differently if you were tested MAP ${ }^{3}$ positive/ negative? ${ }^{1}$

- Do you think MAP can be eradicated from a farm by implementing management changes? ${ }^{1}$ 